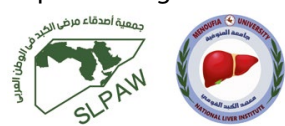

\title{
Melatonin-primed ADMSCs elicit an efficacious therapeutic response in improving high-fat diet induced non- alcoholic fatty liver disease in C57BL/6J mice
}

\author{
Aliasgar Hatimbhai Vohra ${ }^{1}$, Kapil Kumar Upadhyay ${ }^{2}$, Apeksha Suhas Joshi ${ }^{1}$, Hitarthi Swetang Vyas ${ }^{1}$, \\ Jaymesh Thadani ${ }^{3}$ and Ranjitsinh Vijaysinh Devkar ${ }^{1 *}$
}

\begin{abstract}
Background: Stem cells are widely used for therapy including treatment of liver damage. Adipose-derived mesenchymal stem cells (ADMSCs) administered to treat fatty liver are known to improve liver function but their use is restricted due to a poor success rate. This study investigates efficacy of melatonin-primed ADMSCs (Mel. MSCs) in experimentally induced non-alcoholic fatty liver disease (NAFLD).
\end{abstract}

Results: MSCs treated with LPS showed prominent DCFDA fluorescence as compared to the untreated cells. Also, the $\mathrm{JC}-1$ staining had accounted for higher intensity of green monomer and a weak fluorescence of red dimer indicating weaker mitochondrial membrane potential. But melatonin co-treatment could make necessary corrective changes as evidenced by reverse set of results. The overall cell survival was also found to be improved following melatonin treatment as evidenced by the MTT assay. Also, the antioxidant (Nrf2 and Ho-1) and anti-inflammatory genes (II-4 and II-10) showed a decrement in their mRNA levels following LPS treatment whereas the pro-inflammatory genes (Tnf- $a, I I-6$, $T / r-4$, and $L b p)$ showed a reciprocal increment in the said group. Melatonin co-treatment accounted for an improved status of antioxidant and anti-inflammatory genes as evidenced by their mRNA levels. High-fat high-fructose diet (HFFD) fed C57BL/6J mice recorded higher serum AST and ALT levels and fatty manifestation in histology of liver along with lowered mRNA levels of antioxidant (Nrf2, Catalase, and Gss) genes and Hgf. These set of parameters showed a significant improvement in HFFD + Mel.MSC group.

Conclusion: A significant improvement in viability of MSCs was recorded due to lowered intracellular oxidative stress and improves mitochondrial membrane potential. Further, melatonin-primed MSCs accounted for a significant decrement in fatty manifestations in liver and an improved physiological status of NAFLD in HFFD fed C57BL/6J mice. Taken together, it is hypothesized that melatonin priming to MSCs prior to its use can significantly augment the success of stem cell therapy.

Keywords: Melatonin, Non-alcoholic fatty liver disease, Stem cell therapy, Adipose-derived mesenchymal stem cells, NAFLD

\footnotetext{
*Correspondence: rv.devkar-zoo@msubaroda.ac.in

1 Division of Metabolic Physiology and Endocrinology, Department of Zoology, Faculty of Science, The Maharaja Sayajirao University of Baroda, Vadodara, Gujarat 390002, India

Full list of author information is available at the end of the article
}

\section{Background}

The ability of mammalian liver to undergo reparative regeneration in condition of hepatotoxic manifestations by a single or multiple factors is well established. Nonalcoholic fatty liver disease (NAFLD) is characterized by 
fat accumulation and resultant inflammation in hepatocytes [1]. These early symptoms may progress from NAFLD to Non-alcoholic steatohepatitis (NASH); a transition that gets compounded by comorbidity such as type 2 diabetes, dyslipidemia and obesity [2]. Early detection and lack of single therapeutics are major challenges faced by clinicians for treating NAFLD. Current therapeutic strategy comprises of synthetic drugs used for treatment of hyperglycemia and/or hypertriglyceridemia [3]. A variety of herbal extracts and phytopharmaceuticals have also been reported to be effective against experimentally induced NAFLD owing to their antioxidant and free radical scavenging potential but due to a limited success their clinical use is restricted [4].

Stem cell-based therapies have been widely explored as an alternative to conventional therapeutic strategy wherein, mesenchymal stem cells (MSCs) have emerged as a viable option for treating NAFLD. MSCs are known for their immunomodulatory, anti-inflammatory and immunosuppressive properties in degenerative diseases [5]. MSCs are responsive to several signaling molecules such as hormones, growth factors, chemotactic molecules and cytokines [6]. Bone marrow, umbilical cord blood, and adipose tissue-derived MSCs exhibits easy acceptance as an isograft [7]. In mouse model of CCL4induced liver fibrosis, bone marrow-derived MSCs administered via tail vein prevent liver scarring and stimulate liver regeneration [8]. Also, these MSCs could reverse high-fat diet (HFD) induced NAFLD in mice by suppressing CD4+ T lymphocytes [9]. Further, MSCs with upregulated levels of SOD and CAT could effectively reduce systemic inflammation and improve diet induced fatty liver [10]. In pre-clinical and clinical trials, MSCs are known to readily differentiate into hepatocytes [11] but a poor success rate of stem cell therapy was attributed to an inflamed microenvironment in NAFLD [12]. Subtle modifications in stem cell therapy had resulted in an improvement in ischemic acute renal failure [13], inflammatory bowel diseases [12], heart [14], lungs [7], brain [15], rheumatoid arthritis [16], periodontal ligament [17] or knee cartilage [18], and liver function in CCL4 induced liver fibrosis [19]. Hence, it is imperative to appropriately modify the stem cell therapy for a higher efficacy and success rate.

Melatonin (N-acetyl-5-methoxytryptamine), a lipophilic indoleamine tryptophan derivative is synthesized by the pineal gland, skin, retina, gastrointestinal tract and immune cells [20] and is known for regulating circadian rhythm. Also, anti-oxidant [21], anti-neoplastic, anti-inflammatory, neuroprotective [22], and anti-apoptotic properties [23] of melatonin have been reported till date. Further, melatonin induced decrement in body weight gain, increased insulin sensitivity, homeostasis of lipid and glucose metabolism and an improvement in HFD-induced NAFLD in obese mice were reported [24]. Neural stem cells treated with melatonin had lowered expression of pro-inflammatory markers [25] whereas; ADMSCs treated with melatonin underwent proliferation, stemness and self-renewal [26]. Overall, melatonin priming is known to improve the viability of a variety of transformed cells [27] including the mesenchymal stem cells [28].

In liver disorders including NASH, the anti-inflammatory potential of melatonin has been pinned as the reason for its therapeutic potential $[29,30]$. Bone marrow derived MSCs have been reported to improve function of steatotic liver albeit with limited success [31]. But the merits of adipose derived MSCs in treating NAFLD and possible advantages of prior melatonin priming are not known [32]. This study is designed to evaluate the merits of melatonin priming, to adipose derived MSCs and their possible improvement in their efficacy in treating experimentally induced NAFLD.

\section{Methods \\ Chemicals}

Melatonin, hematoxylin, eosin, collagenase type 1, and lipopolysaccharide (LPS) were purchased from Sigma Aldrich (St. Louis, MO, USA). Methanol, ethanol, dimethyl sulphoxide (DMSO) and 3-(4, 5-dimethylthiazol2-yl)-2, 5-diphenyl tetrazolium bromide (MTT) were purchased from Sisco Research Laboratory Pvt. Ltd. (Mumbai, India). Molecular biology reagents except iScriptcDNA synthesis kit (Bio-Rad, CA, USA) and all other reagents such as TRIzol, DreamTaq Green master mix, and SYBR select master mix were procured from Invitrogen (CA, USA). Chemicals for cell culture like Dulbecco's modified Eagle's medium (DMEM), fetal bovine serum (FBS), trypsin phosphate versene glucose (TPVG), and antibiotic-antimycotic solution were purchased from Hi-media Laboratories (Mumbai, India). ENZOPAK aspartate aminotransferase (AST), alanine transaminase (ALT), alkaline phosphatase (ALP), total lipids (TL), total cholesterol (TC), triglycerides (TG), low-density lipoprotein (LDL), very low-density lipoprotein (VLDL), high-density lipoprotein (HDL), and glucose kits were purchased from Reckon Diagnostics (Vadodara, Gujarat). RNA-later was purchased from Ambion Inc. (USA).

\section{ADMSCs isolation, characterization, and melatonin priming}

Adipose derived mesenchymal stem cells (MSCs) were isolated from 8-week-old male C57BL/6J mice ( $20 \pm 2$ g) as per Yu et al. [33]. Briefly, bilateral fat pads in retroperitoneal cavity were collected, minced in small pieces 
using sterile scissors, and digested ( $45 \mathrm{~min}$ in water bath at $37{ }^{\circ} \mathrm{C}$ ) in equal amount of collagenase- 1 in incomplete media. After the digestion, tubes were centrifuged (300 $\mathrm{g}$ for $5 \mathrm{~min}$ ) and mixed vigorously for 5-10 s. This step was repeated three times to obtain a dark red cells pellet. That was resuspended in complete media and seeded in T25 flask. Media was changed once daily till the cells were $80-90 \%$ confluent. At the 4th passage cells were fixed with freshly prepared $2 \%$ Paraformaldehyde (PFA) for 10 minutes at room temperature and permeabilized with $0.1 \%$ Triton $\mathrm{X}-100$ for $3-5$ min on ice. AD-MSCs were examined for expression of surface markers (CD34, CD44, CD45, and CD105) by flow-cytometry. Briefly, the cultured cells were suspended in cold DPBS at the dilution of $10^{6}$ cells $/ \mathrm{ml}$. Incubation with primary antibodies (CD34, CD44, CD45, and CD105) was followed by exposure to secondary conjugated antibody at $4{ }^{\circ} \mathrm{C}$ for $30 \mathrm{~min}$, and the complex was analyzed by flow-cytometry. MSCs were cultured in T-25 flask and, at passage 4, were incubated in presence of $5 \mu \mathrm{M}$ melatonin (dissolved in ethanol and diluted in saline to 5\%) for $24 \mathrm{~h}[34,35]$.

\section{Cell viability (MTT) assay}

Mesenchymal stem cells $\left(6 \times 10^{3}\right.$ cells/ well $)$ were maintained in 96-well culture plates (Tarson India Pvt. Ltd.) for $24 \mathrm{~h}$ with or without LPS ( 1 and $3 \mu \mathrm{g} / \mathrm{ml}$ ) and melatonin $(5 \mu \mathrm{M})$. Later, $10 \mu \mathrm{l}$ of 3-(4, 5-dimethylthiazol2-yl)-2, 5-diphenyltetrazolium bromide (MTT, $5 \mathrm{mg}$ / $\mathrm{ml}$ ) was added to the wells and plates were incubated at $37{ }^{\circ} \mathrm{C}$ for $4 \mathrm{~h}$ [36]. Subsequently, the culture media was discarded and wells were washed with PBS. The resultant formazan formed was dissolved in $150 \mu \mathrm{l}$ of DMSO and absorbance was read at $540 \mathrm{~nm}$ using a Synergy HTX Multimode reader (BioTek, USA).

\section{Intracellular oxidative stress}

MSCs were maintained for $24 \mathrm{~h}$ as mentioned above with or without LPS ( 1 and $3 \mu \mathrm{g} / \mathrm{ml}$ for $24 \mathrm{~h}$ ) and melatonin $(5 \mu \mathrm{M})$. ROS mediated intracellular oxidative stress in MSCs was studied using $7.5 \mu \mathrm{M}$ 2,7-dichlorodihydrofluoroscein diacetate (CM-H2-DCFDA) stain $\left(37^{\circ} \mathrm{C}\right.$ for $30 \mathrm{~min}$ ) [37]. Cells were photographed using Floid cell imaging station (Invitrogen, USA) and their fluorescent intensity was quantified using Image $(\mathrm{NIH}$, Bethesda, USA) software.

\section{Mitochondrial membrane potential}

MSCs were maintained for $24 \mathrm{~h}$ as mentioned above with or without LPS ( 1 and $3 \mu \mathrm{g} / \mathrm{ml})$ and melatonin $(5 \mu \mathrm{M})$. Mitochondrial membrane potential was assessed using 5,5',6,6'-tetrachloro-1, $1^{\prime}, 3,3^{\prime}$-tetraethylbenzimidazolcarb ocyanine iodide JC-1 stain $(5 \mu \mathrm{g} / \mathrm{ml})$ in pre-warmed $1 \times$ PBS for $30 \mathrm{~min}$ at $37^{\circ} \mathrm{C}[38,39]$. Cells were observed and photographed using Floid cell imaging station (Invitrogen, USA) and fluorescent intensity was quantified using ImageJ (NIH, Bethesda, USA) software [40].

\section{mRNA studies of key marker genes in MSCs and liver of C57BL/6J mice}

Total RNA was isolated from the MSCs and liver of control and various experimental groups using TRIzol reagent and quantified using a nanodrop spectrophotometer (Thermo scientific, Ltd.). Later, samples $\left(A_{260} / A_{280}\right.$ $>1.9$ ) were processed for cDNA synthesis using iScript cDNA Synthesis kit (Bio-Rad, CA, USA) at $37{ }^{\circ} \mathrm{C}$ for $1 \mathrm{~h}$ (using a T 100 Bio-Rad 96-well thermal cycler; Bio-Rad, CA, USA). mRNA levels of key genes in MSCs (Tlr-4, Lbp , Nrf2, Ho-1, Tnf- $\alpha, I l-6, I l-4, I l-10)$ and in liver (Nrf2, Sod, Catalase, Gss, Il-4, and $H g f)$ were quantified by qPCR analysis (Quant-Studio-3, Life Technologies, CA, USA) using SYBR Select Master Mix [40] using primers sequences shown in Table 1. The following two steps thermal cycling profile was used for qPCR analysis, step I (cycling step): $95^{\circ} \mathrm{C}$ for $10 \mathrm{~min}, 95^{\circ} \mathrm{C}$ for $15 \mathrm{~s}, 60^{\circ} \mathrm{C}$ for $1 \mathrm{~min}$ and $95^{\circ} \mathrm{C}$ for $15 \mathrm{~s}$ for 40 cycles. step II (melt curve step): $60^{\circ} \mathrm{C}$ for $15 \mathrm{~s}, 60^{\circ} \mathrm{C} 1 \mathrm{~min}$ and $95^{\circ} \mathrm{C}$ for $30 \mathrm{~s}$.

The data obtained was normalized to the Gapdh (internal control) and analyzed using $2-\Delta \Delta C$ T method.

\section{Experimental animals and their treatment with MSCs}

C57BL/6J mice (24 male mice; $6-8$ weeks of age; $18-22$ g) were procured (Zydus Research Centre) Ahmadabad, India, housed in clean polypropylene cages with laboratory chow diet and water ad libitum in Committee for the Purpose of Control and Supervision of Experiments on Animals (CPCSEA), India, approved animal house facility of Department of Zoology, The Maharaja Sayajirao University of Baroda, Vadodara, Gujarat, India (Approval No. 827/GO/Re/S/04/CPCSEA). After an acclimatization of 10 days, mice were randomly divided into 4 groups of 6 mice per group viz. Group I (fed with laboratory chow diet), groups II, III, and IV were fed with HFFD (high-fat diet $+20 \%$ Fructose through water) and water ad libitum for 16 weeks [40]. At the end of 13th week group III was treated with $\left(1 \times 10^{6}\right.$ cells in $\left.0.2 \mathrm{ml}\right)$ MSCs and group IV with $5 \mu \mathrm{M}$ melatonin-primed MSCs via tail vein [19]. The experimental protocol was carried out according to the guidelines of the Committee for the Purpose of Control and Supervision of Experiments on Animals (CPCSEA), India, and approved by the Institutional Animal Ethical Committee (IAEC). Our previous study had revealed that results obtained in groups fed with normal chow diet and injected MSCs or melatonin-primed MSCs (MSC + $\mathrm{NCD}$ or Mel.MSC+NCD respectively) were comparable to that of control; hence they are not showcased herein (Unpublished observations). 
Table 1 PCR primers sequences of the genes analyzed

\begin{tabular}{|c|c|c|c|}
\hline Sr. no. & Gene & Forward primer & Reverse primer \\
\hline 1 & GAPDH & 5'-TGTGAACGGATTTGGCCGTA-3' & 5'-ACTGTGCCGTTGAATTTGCC-3' \\
\hline 2 & TLR-4 & 5'-TTTGCTGGGGCTCATTCACT-3' & 5'-GACTCGGCACTTAGCACTGT-3' \\
\hline 3 & LBP & 5'-TGTTACCACATGACTCCGGC-3' & 5'-AGGTGGGCAGGATCACAAAG-3' \\
\hline 4 & NRF2 & 5'-CGAGATATACGCAGGAGAGGTAAGA-3' & 5'-GCTCGACAATGTTCTCCAGCTT-3' \\
\hline 5 & $\mathrm{HO}-1$ & 5'-ACATCGACAGCCCCACCAAGTTCAA-3' & 5'-CTGACGAAGTGACGCCATCTGTGAG-3' \\
\hline 6 & TNF-a & 5'-GTGGAACTGGCAGAAGAG-' & 5'-AATGAGAAGAGGCTGAGAC-3' \\
\hline 7 & $\mathrm{IL}-6$ & 5'-TGGATGCTACCAAACTGGAT-3' & 5'-CCTCAAAGCCAAGATGAGAA-3' \\
\hline 8 & $\mathrm{IL}-4$ & 5'-GTAGGGCTTCCAAGGTGCTT-3' & 5'-GGCATCGAAAAGCCCGAAAG-3' \\
\hline 9 & $\mathrm{IL}-10$ & 5'-AAGGGTTACTTGGGTTGCCA-3' & 5'-TTCAGCTTCTCACCCAGGGA-3' \\
\hline 10 & HGF & 5'-TGAGTTATGTGCTGGGGCTG-3' & 5'-CACATCCACGACCAGGAACA-3' \\
\hline 11 & CAT & 5'-CTGGATGGATTCTCCCCCGC-3' & '-TCAGGAAACGGCATCAAAAGC-3' \\
\hline 12 & GSS & 5'-AACGAGCGAGTTGGGATG-3' & 5'-TATGTCACCACGTCGGAGGA-3' \\
\hline 13 & SOD & 5'-TTGGCCTGTGGAGTGATTGG-3' & 5'-AGCCCAGTCAAAGGAGTCAC-3' \\
\hline
\end{tabular}

\section{Experimental procedure}

At the end of 16 weeks, animals were fasted overnight and whole blood was collected by retro-orbital sinus puncture under mild isoflurane anesthesia [41-44]. Isoflurane is the most frequently used halogenated anesthetic in animal research and does not produce any significant differences in liver injury, inflammation, and regeneration [41, 44]. Whole blood was centrifuged (at $4{ }^{\circ} \mathrm{C}$ and $3000 \mathrm{rpm}$ for $10 \mathrm{~min}$ ) and serum was collected and stored. Later, mice were sacrificed using isoflurane under minimum stress and liver was collected and stored in $10 \%$ formalin (for histopathology) and in RNAlater (for mRNA studies). No mortality was observed in any of the experimental groups during the period of study.

\section{Serum biochemical parameters}

Circulating titers of enzymes indicative of liver function (AST, ALT, and ALP), fasting blood glucose [45] and serum lipid profile (TL, TC, TG, LDL, VLDL, and HDL) [46] were estimated using commercially available kits (Reckon Diagnostic kits, Vadodara, Gujarat, India).

\section{Microscopic evaluations}

Liver samples were fixed in $10 \%$ formalin for $48 \mathrm{~h}$, and then embedded in paraffin. Tissues sections ( $5 \mu \mathrm{m}$ thick) were deparaffinized and stained with hematoxylin and eosin (HXE) [37, 40].

\section{Quantification of cellular immunofluorescence}

Immunofluorescent images were captured using Floid cell imaging station and were analyzed using ImageJ (NIH, Bethesda, USA). Cell area, integrated density and mean gray value were measured for each selected cell. Also, mean gray values (fluorescence intensities) of four different background areas were measured in every image for normalization of background auto fluorescence. The resultant values were normalized with the background fluorescence of 4 areas. The corrected total cell fluorescence (CTCF) for each cell was calculated as [47]:

$$
\mathrm{CTCF}=\text { Integrated density }-(\text { area of cell } \times \text { mean of background flourescence })
$$

Fluorescent intensities of about 70 cells from 5 to 8 different images were recorded for each experimental group for statistical analysis.

\section{Statistical analysis}

Results were expressed as means \pm standard deviation (SD) and analyzed by one-way analysis of variance (ANOVA) with Bonferroni's multiple comparison tests using Graph Pad Prism 5 (CA, USA). " $p<0.05,{ }^{* * *} p<0.01$, and ${ }^{* * * *} p<0.001$ is when LPS treated or HFFD is compared with control. $\# p<0.05$, \#\#p<0.01, and \#\#\#< 0.001 is when LPS + Mel is compared with LPS-treated group.

\section{Results}

Characterization of MSCs, intracellular oxidative stress, and cell viability assay

Adipose derived mesenchymal stem cells (MSCs) were isolated from the perirenal and visceral fat pads of healthy $\mathrm{C} 57 \mathrm{BL} / 6 \mathrm{~J}$ mice and were characterized using positive (CD44 and CD105) and negative (CD34 and CD45) surface markers (Figure S1). Flow cytometric studies had shown $98.18 \%$ of CD44 and $97.05 \%$ of CD105 (positive) cells. Lipopolysaccharide (LPS; 1 and $3 \mu \mathrm{g} / \mathrm{ml}$ ) treatment accounted for a dose-dependent decrement $(\sim$ 
(A)

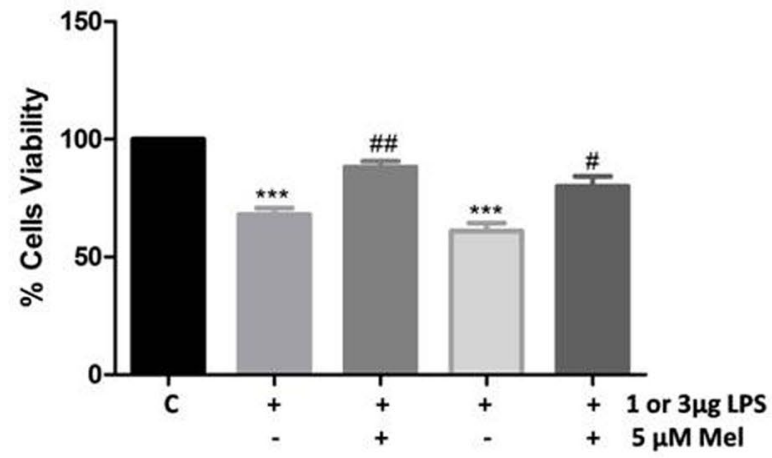

(C)

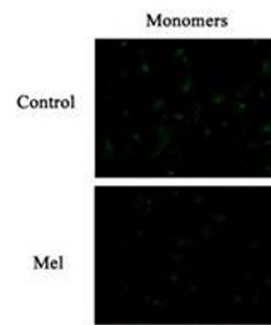

I LPS
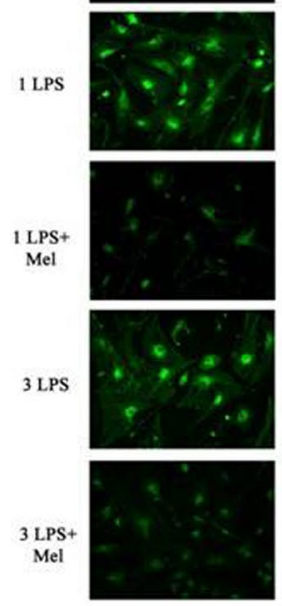
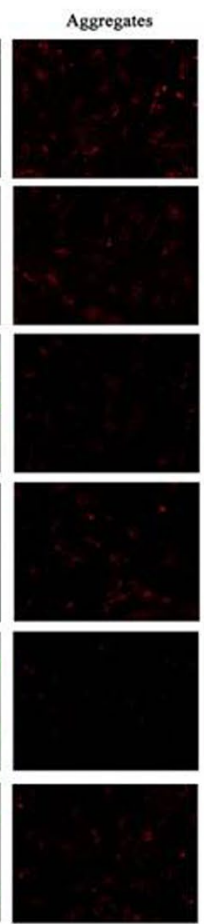
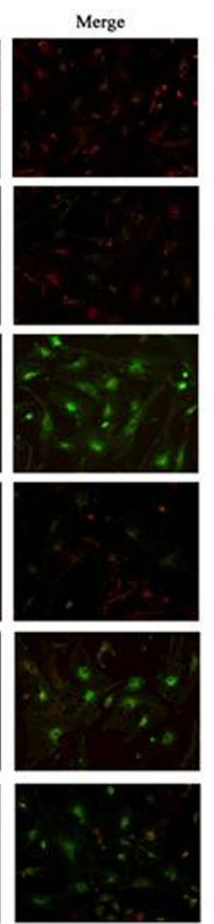

(B)

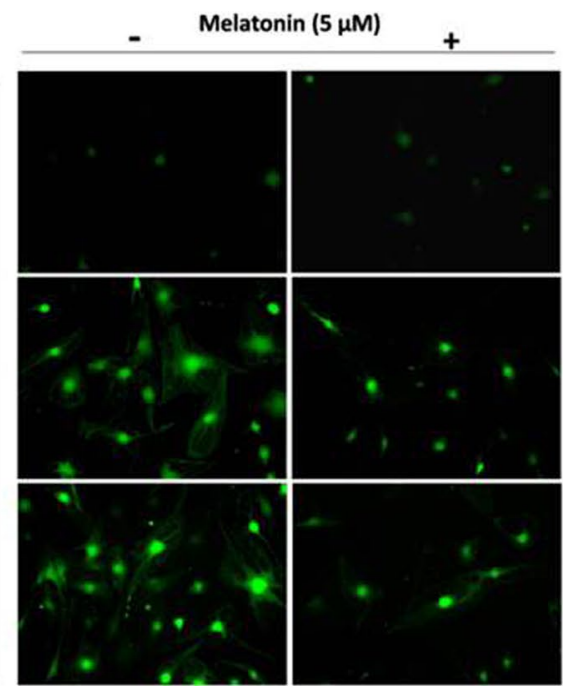

Control

1 LPS

3 LPS
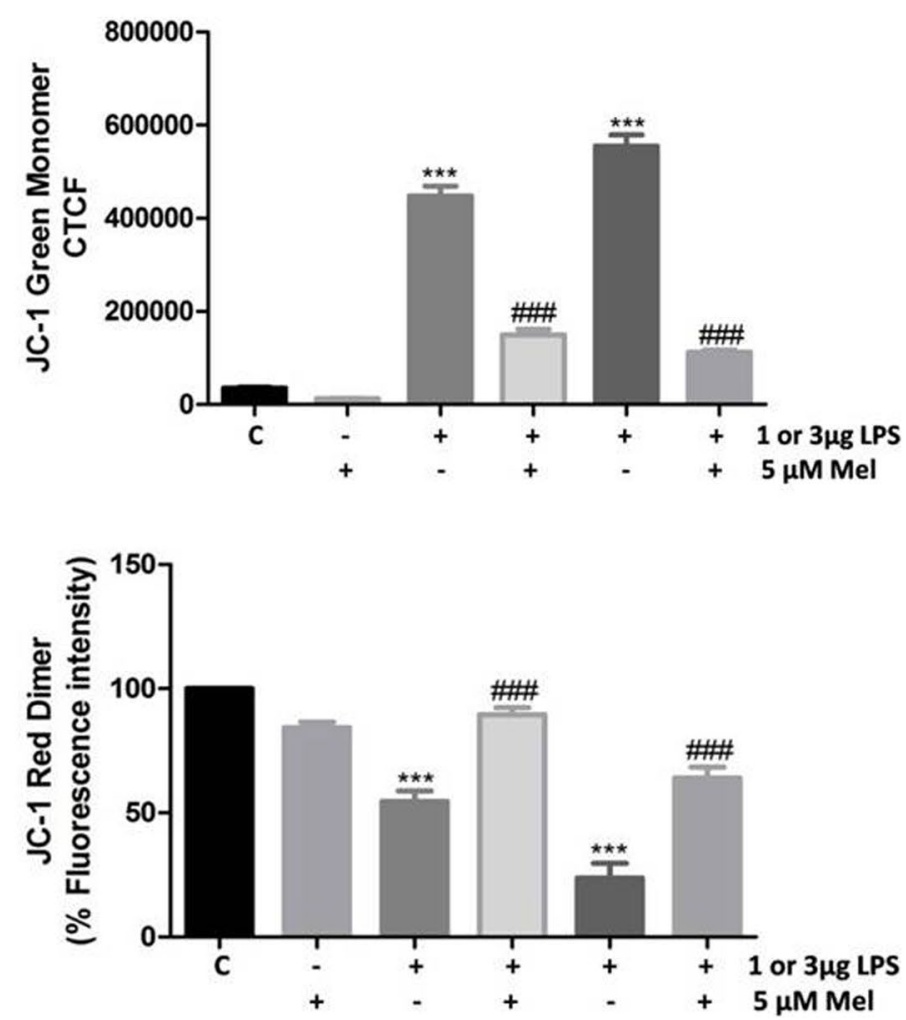

Fig. 1 Adipose-derived MSCs treated with lipopolysaccharide (LPS) and/or melatonin (Mel). Mel alleviates LPS-induced (A) cytotoxicity; MTT assay, (B) intracellular oxidative stress; DCFDA staining and (C) mitochondrial membrane potential; JC-1 staining. Data expressed as mean \pm S.E.M. for $n=$ 3. ${ }^{*} p<0.05,{ }^{* *} p<0.01$, and ${ }^{* * *} p<0.001$ is when LPS treated is compared with control. \#p $<0.05$, \#\#p<0.01 and \#\#\#p<0.001 is when LPS + Mel is compared with LPS-treated group

$25 \%$ and $\sim 40 \%$ respectively; $p<0.001$ ) in cell viability in MSCs as evidenced by the (MTT) assay (Fig. 1A). Also, a prominent green fluorescence in these cells was observed following DCFDA staining that implied towards a heightened intracellular oxidative stress (Fig. 1B). LPS +5 $\mu \mathrm{M}$ melatonin co-treatment accounted for 20-25\% 
improvement in cell viability $(p<0.05)$ and relatively weaker DCFDA fluorescence as compared to LPS-treated MSCs.

\section{Mitochondrial membrane potential (JC-1 staining)}

MSCs were stained with JC-1 to assess the changes in mitochondrial membrane potential $(\triangle \Psi \mathrm{m})$. MSCs treated with LPS ( 1 and $3 \mu \mathrm{g}$ LPS doses) recorded prominent green (monomer) and weak red (dimer) fluorescence implying towards a significant decrement $(p<$ $0.001)$ in mitochondrial membrane potential. Improvement in the fluorescence following co-treatment with 5 $\mu \mathrm{M}$ melatonin suggested an improvement $(p<0.001)$ in mitochondrial membrane potential as compared to LPStreated groups (Fig. 1C).

\section{mRNA levels of pro, anti-inflammatory, and antioxidant genes in MSCs}

Tlr4 and Lbp are key genes for assessing LPS induced inflammation and, in our study, LPS treated MSCs (for $24 \mathrm{~h}$ ) recorded a significant increase in the mRNA levels of the said genes as compared to control $(p<0.001)$
(Fig. 2A). Further, mRNA levels of Nrf2 were non-significantly decreased following LPS treatment (Fig. 2B) thus implying towards a compromised cellular antioxidant status. LPS + Mel group accounted for lower Tlr-4 ( $p<$ $0.001), \operatorname{Lbp}(p<0.05)$, and higher Nrf2 as compared to LPS-treated group. However, $\mathrm{HO}-1$ levels were found to be elevated in all the experimental groups (Fig. 2B). Further, LPS treated MSCs recorded a significant increment in mRNA levels Tnf- $\alpha(p<0.01)$ and Il-6 $(p<0.05)$ and a decrement in Il-4 $(p<0.01)$ and Il-10 $(p<0.05)$. Melatonin co-treatment to these cells accounted for a significant decrement in Tnf- $\alpha$ and Il-6 mRNAs $(p<0.01)$ and; a significant increment in $\mathrm{Il}-4(p<0.001)$. $\mathrm{Il}-10 \mathrm{mRNA}$ levels were found to be non-significantly higher in this group (Fig. 3A, B).

\section{Serum AST, ALT, and lipid profile}

Food and water intake of C57BL/6J mice was monitored (16 weeks) during the period of study. HFFD treatment accounted for a significant increment in body weight gain $(p<0.001)$, liver weight $(p<0.001)$, and liver:body weight ratio $(p<0.05)$ as compared to control (Figure S2, A, B).

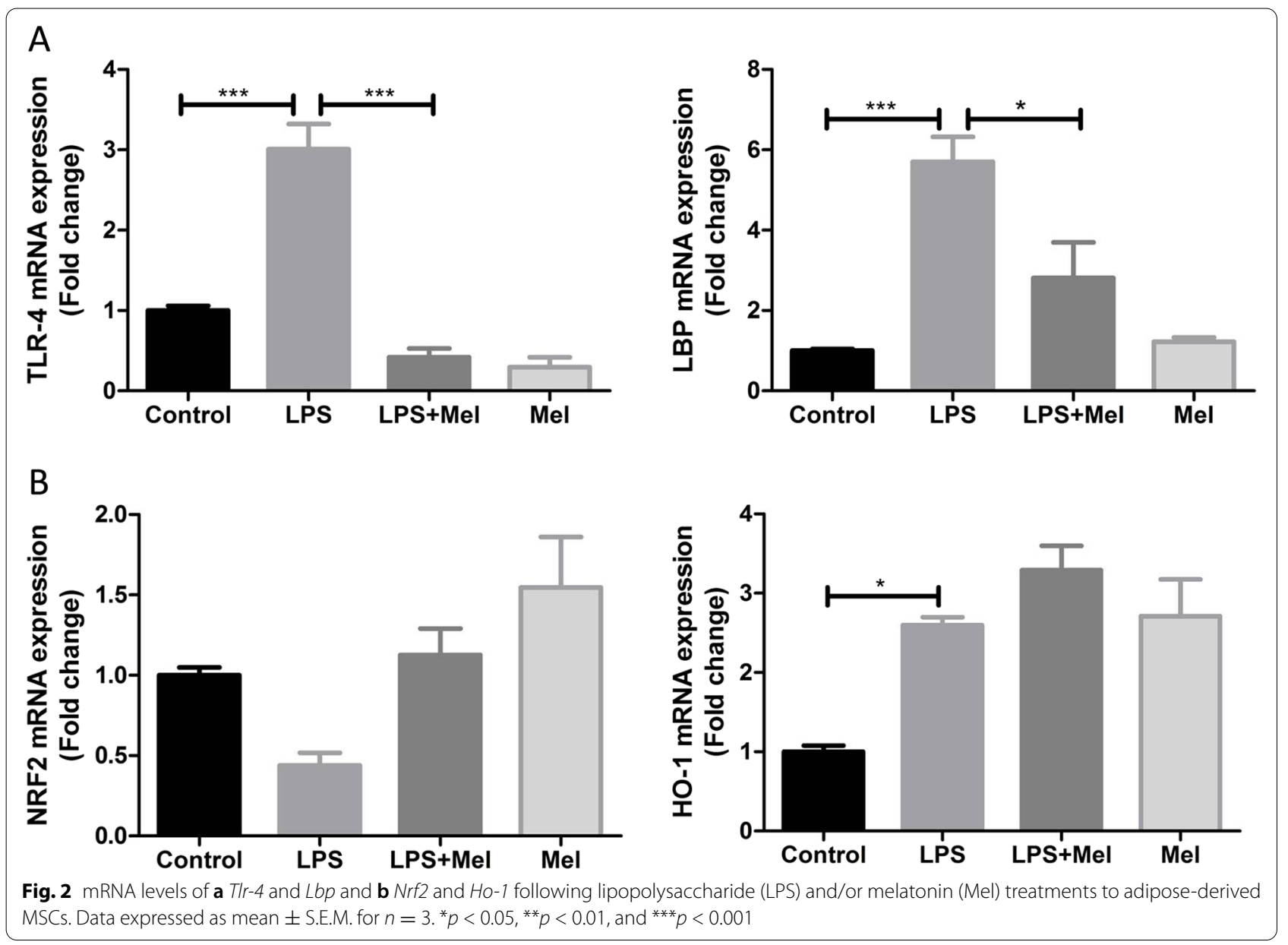




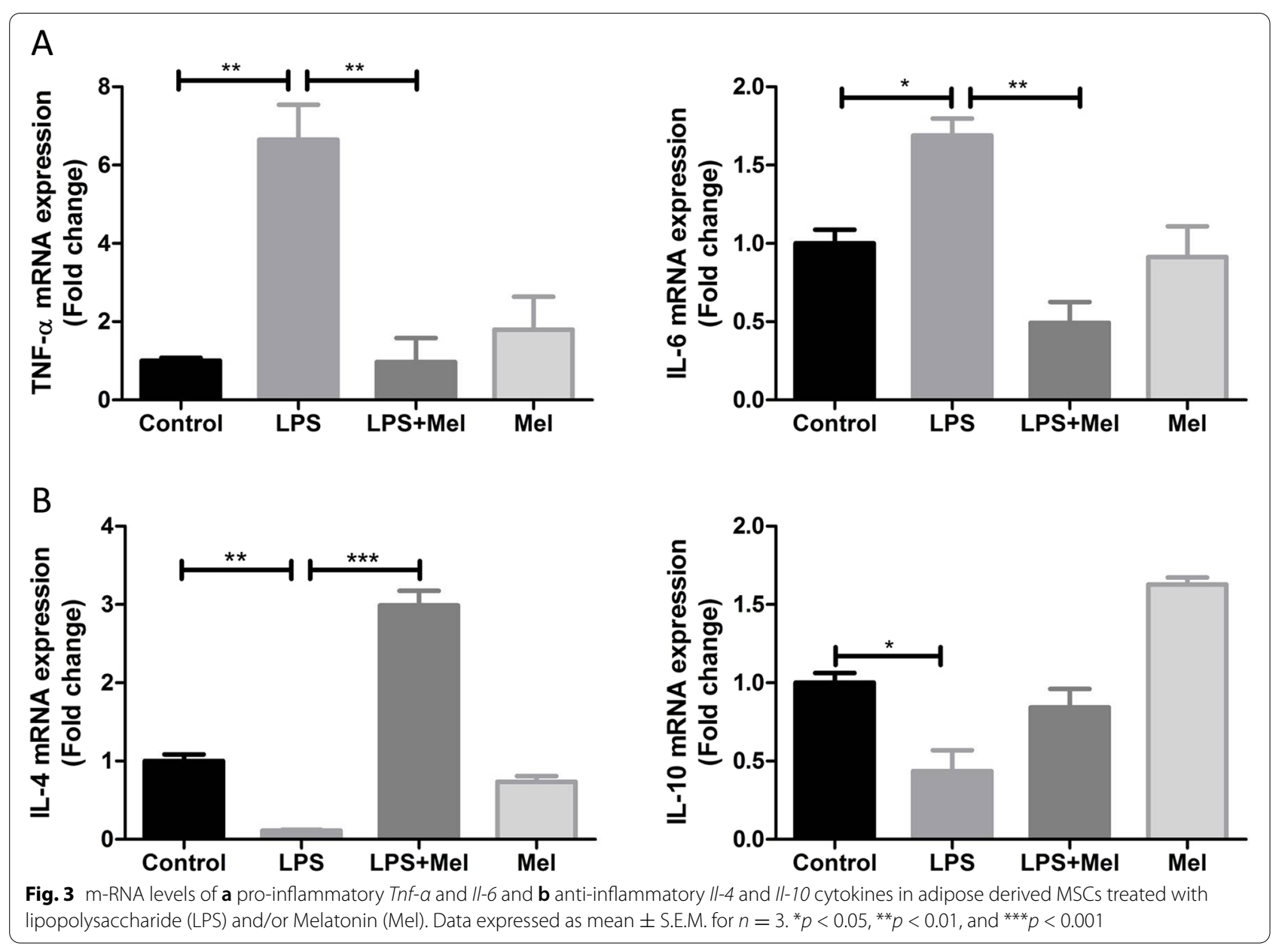

Significant hyperglycemia was recorded in serum $(p<$ 0.001 ) of HFFD group but HFFD + MSCs had recorded a significantly decrement $(p<0.001)$. Also, non-significant hyperglycemia was recorded in HFFD + melatoninprimed MSCs (Mel.MSC) group. Circulating titers of serum AST and ALT were significantly elevated in the HFFD group $(p<0.001)$ but, MSC and Mel.MSC groups accounted for a significant decrement in titers of the ALT $(p<0.01)$ and AST $(p<0.05)$. ALP levels did not show any significant alterations in all the experimental groups (Fig. 4).

Significantly higher levels of serum total lipids $(p<$ $0.01)$, total cholesterol $(p<0.001)$, triglycerides $(p<$ $0.01)$, and LDL cholesterol $(p<0.001)$ were recorded in HFFD group whereas; significant decrement was recorded in serum HDL-cholesterol $(p<0.05)$. Though, HFFD + MSC group had recorded non-significant decrements in total lipids, total cholesterol, triglycerides, LDL cholesterol, and VLDL cholesterol, a significant increment in HDL cholesterol $(p<0.05)$ was recorded in this group. A similar trend was witnessed in HFFD
+ Mel.MSC group with respect to the said parameters wherein, decrements in total lipids $(p<0.05)$, total cholesterol $(p<0.01)$, and LDL cholesterol $(p<0.01)$ were significant (Fig. 5).

\section{Histological assessment of liver tissue}

The liver tissue sections showed normal hepatic cords radiating from the central vein and a preserved hepatic architecture. Also, the hepatocytes were polygonal and of uniform size with granular cytoplasm. The cells in vicinity of the portal vein showed healthy cellular characteristics. Liver of HFFD group showed distorted hepatic cords, ballooning hepatocytes with rarefied cytoplasm and macrovesicular steatosis. Also, the infiltration of inflammatory cells was evident in the said tissue. Treatment of HFFD fed mice with MSCs or Mel.MSCs led to a visible decrement in the fatty hepatocytes and macrovesicular steatosis. Overall, a normal cellular architecture could be observed in these groups with minimal infiltration of cells due to inflammation (Fig. 6). 

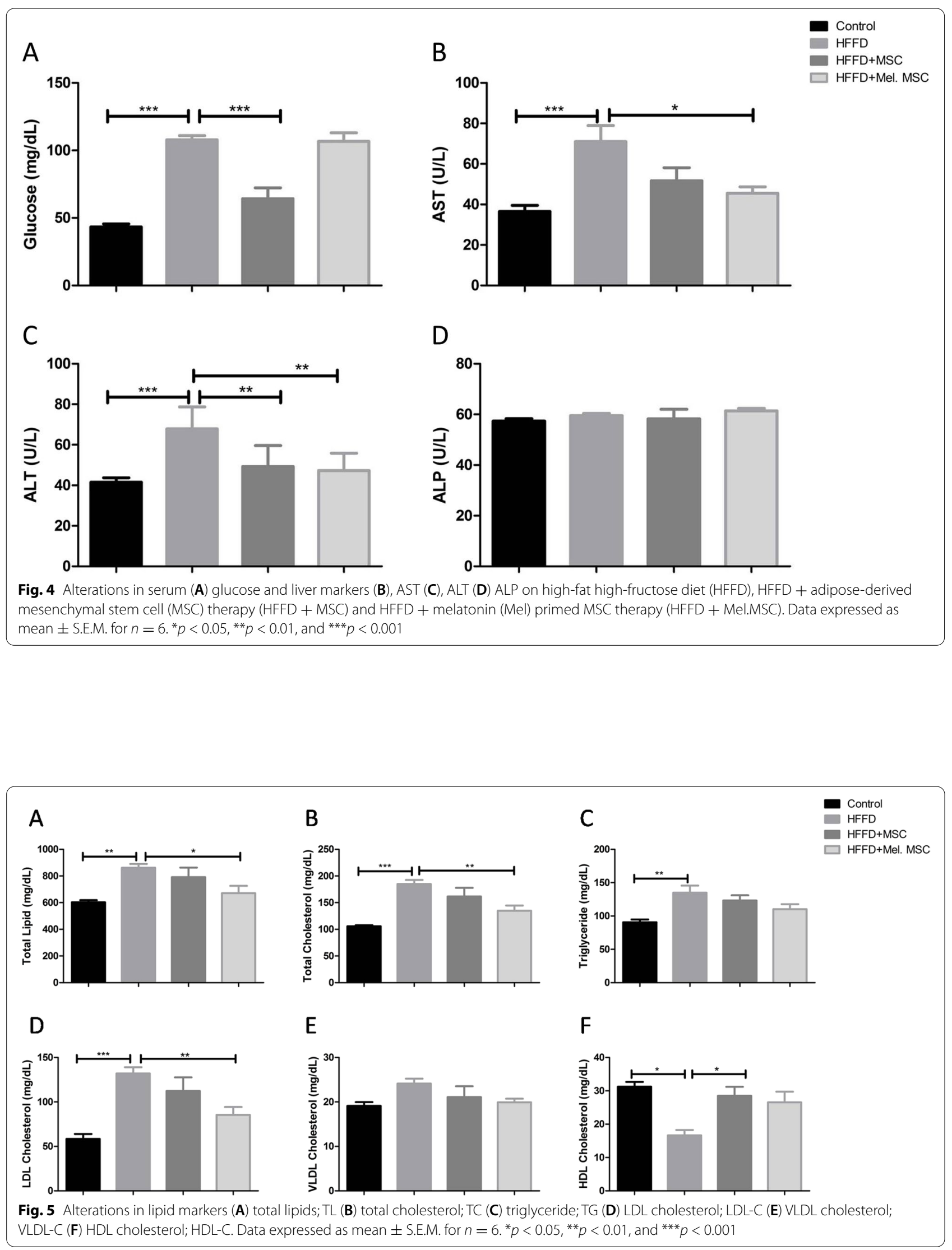


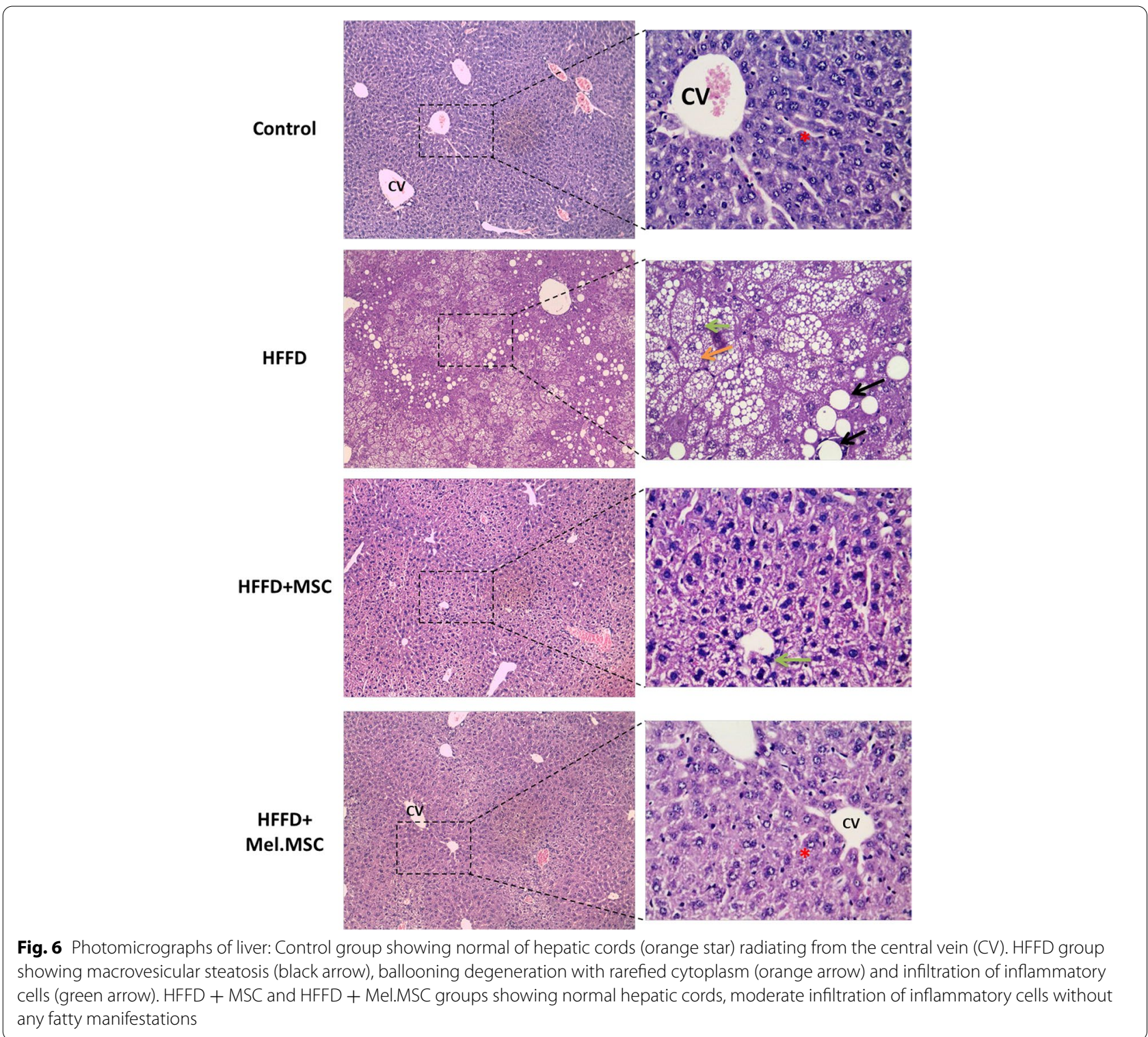

mRNA levels of hepatic Nrf2, Sod, Catalase, and Gss

HFFD group had recorded a decrement in mRNA levels of Catalase and Gss whereas; the Nrf2 and Sod levels were unchanged. However, Nrf2 $(p<0.01)$, catalase $(p<$ $0.01)$, and Gss $(p<0.01)$ mRNA were higher in HFFD + MSC and HFFD + Mel.MSC groups. The mRNA levels of Sod showed non-significant changes in all these experimental groups (Fig. 7).

\section{mRNA levels of hepatic II-4 and $\mathrm{Hgf}$}

The mRNA levels of anti-inflammatory marker gene Il-4 was found to be lowered in HFFD group. However, both HFFD + MSC $(p<0.01)$ and HFFD + Mel.MSC $(p$ $<0.001)$ groups had recorded significant increment in
mRNA levels of $I l-4$. Hgf has a mitogenic property in liver and accounts for its regeneration. In our study, all the three experimental groups had recorded an increment in mRNA levels of $H g f$ with the most significant increase recorded in HFFD + Mel.MSC group $(p<0.05)$ (Fig. 7).

\section{Discussion}

The observations made in this study suggest that administration of MMSCs in HFFD-fed mice results in improvement in functional status and histological features of liver. Currently there is no single US-FDAapproved pharmacological drug for treatment of NAFLD or NASH. The complications associated with liver transplantation create the earnest need for alternative 


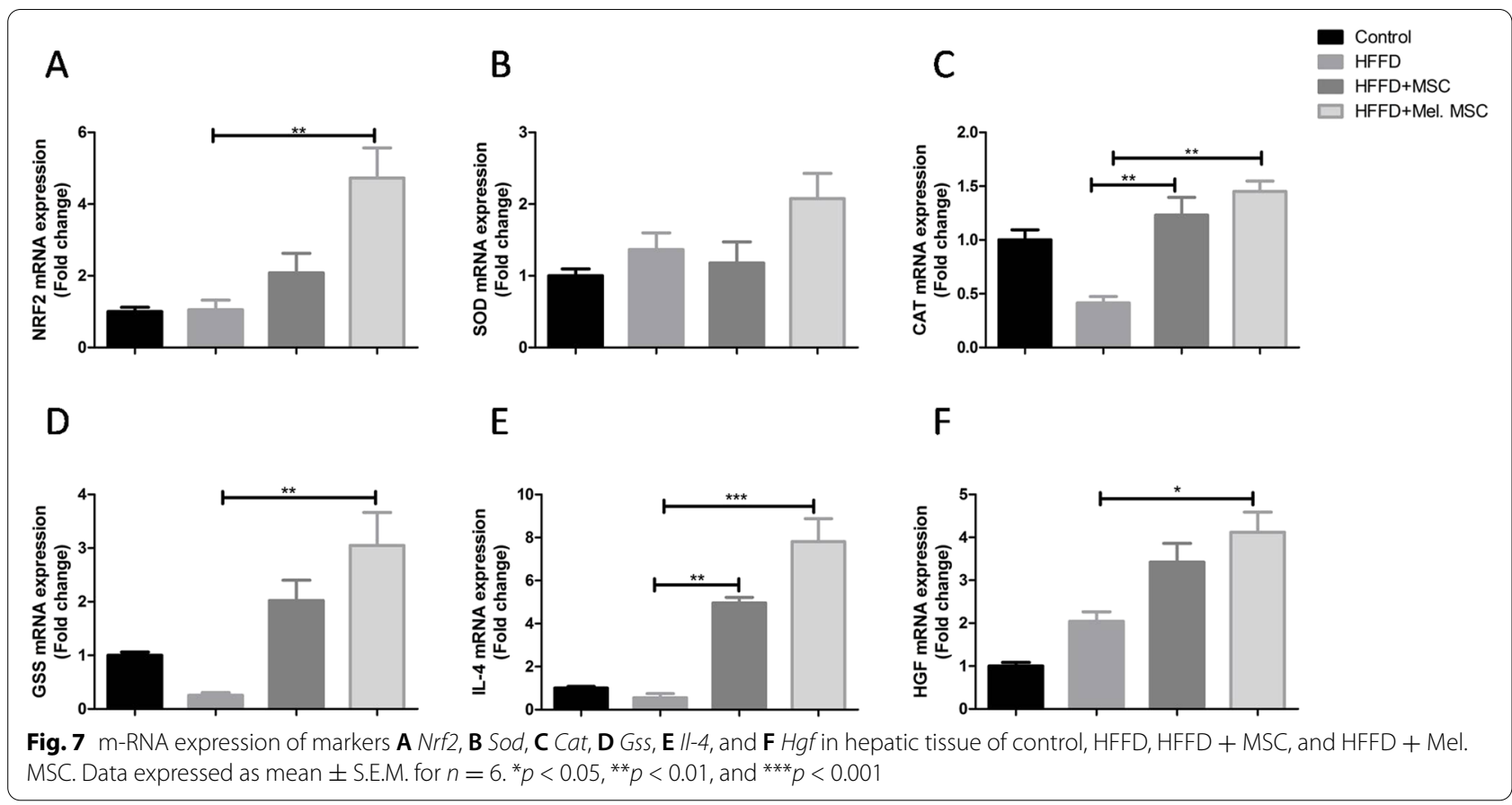

therapeutic options. Stem cell therapy had shown varying degrees of success in treating liver diseases but an inflamed hepatic microenvironment often results in low survival ratio of transplanted cells [48]. In the present study, melatonin-primed adipose derived mesenchymal stem cells (MSCs) were administered to high-fat highfructose diet (HFFD) fed mice and the possible improvement in success rate of transplant with respect to liver function was put to scrutiny. Based on the anti-oxidant attributes of melatonin we had hypothesized that melatonin primed MSCs can possibly improve the functional status of a fatty liver. Intracellular oxidative stress and mitochondrial dysfunction plays a crucial role in various cellular activities including cell growth, survival and death. Research groups had shown that exogenous stressors such as tert-butyl hydroperoxide (t-BHP), hydrogen peroxide $\left(\mathrm{H}_{2} \mathrm{O}_{2}\right)$, tumor necrosis factor alpha (TNF- $\alpha$ ), or lipopolysaccharides (LPS) produced an heightened intracellular oxidative stress in a variety of cell lines [49]. Also, LPS treatment causing mitochondrial ROS production in microglial cells with an upregulation of proinflammatory mediators [50]. In bone marrow-derived macrophages, LPS induced ROS signaling has been reported to be downregulated in the inner mitochondrial membrane UCP2 (uncoupling protein 2) [51]. Also, LPS mediated production of nitric oxide $(\mathrm{NO})$ and ROS that leads to nuclear translocation of NF- $\mathrm{kB}$ in murine macrophages. In our study, LPS-treated MSCs symbolize an inflamed microenvironment in a fatty liver. Hence, an improvement in toxicity indices, intracellular oxidative stress, and mitochondrial membrane potential of LPS + melatonin-treated MSCs generates the 'proof of concept' and forms the basis of our study.

LPS-mediated activation of SIRT1/NRF2 pathway and the resultant oxidative stresses have been reported to be attenuated following melatonin treatment [52]. Also, studies with human ADMSCs had reported an upregulation of cellular prion protein ( $\mathrm{PrPC})$ and lowered ER stress in ADMSCs treated with melatonin [53]. Melatonin is also known to prevent senescence of canine ADMSCs by activating $N r f 2$ via MT1/MT2 receptors [54]. Hence, the observed upregulation of Nrf2 mRNA following melatonin treatment recorded in our study is in agreement with the published reports. LPS mediated inflammatory changes in kupffer cells and upregulation of TLR4 and LBP has reported [55]. In our study, melatonin treatment could successfully alleviate changes in the said parameters and further had accounted for a decrement in mRNA levels of pro-inflammatory markers (Tnf- $\alpha$ and Il-6) and increment in anti-inflammatory markers ( $\mathrm{Il}-4$ and $\mathrm{Il}-10$ ). These observations corroborate with reported upregulation of anti-inflammatory markers that inhibit synthesis and release of pro-inflammatory markers [56]. Overall, this part of the study had justified the use of melatonin in alleviating LPS induced inflammation and had accounted for an improved survival status of MSCs.

Mesenchymal stem cells have been reported to differentiate into hepatocyte like cells and contributing towards an improved liver function [11]. Also BMMSCs have been reported to improve CCL-4 induced liver 
fibrosis in mice [8]. Melatonin pre-treatment to ADMSCs had reduced apoptosis in an ischemic diseases model [57] and had improved homing of MSCs in liver of CCL4 treated rats [19]. Hepatocellular injury like apoptosis and ballooning or enlarged hepatocytes with a clear reticular cytoplasm are characteristic features of NAFLD and have been reported in HFD fed [40], MCD diet fed [58], and gene knockout mouse models [59, 60]. The said changes occur in correlation with higher circulating titers of total cholesterol and triglycerides [40, 61]. In our study, the liver of HFFD fed mice showed fatty changes in hepatocytes, macrovesicular steatosis, infiltration of inflammatory cells and elevated parameters of serum lipid profile. However, an improvement in the said histological parameters is attributable to the administration of MSCs that are known to improve hepatic histoarchitecture and liver function through an autocrine and/or paracrine mechanism $[62,63]$. An improved status of serum lipid profile and higher titers of HDL-c in melatonin primed MSC treated group are indicative of improved systemic lipid load and metabolism. An improvement in physiological status of fatty liver (lower AST and ALT) observed in experimental group treated with melatonin primed MSCs are the highlight of our study.

The mechanism of repair of fatty liver is yet unclear but study by Domingues et al. (2019) had reported that antioxidant-upregulated MSCs have lower oxidative stress, systemic inflammation and an improved liver function in high-fat diet induced obesity in [10]. Also, UC-MSCs could ameliorate NAFLD and regulate lipid metabolism by increasing the expression of fatty acid oxidation genes in $d b / d b$ mice [60]. Further, upregulation of SOD and downregulation of apoptotic markers in melatonin primed MSCs had resulted in lowering of ROS production. In our study, an increment in the expression of Sod, Gss, and Nrf2 in Mel.MSC group is in agreement with these reports. A recent study from our lab had shown that carbon monoxide releasing molecule A-1 had led to an improved oxidative stress and mitochondrial function in a steatotic liver of C57BL/6J mice via activation of NRF2-ARE pathway [40]. Hence, the observed improvement in fatty changes in liver of Mel.MSC mice is possibly mediated via an improved intracellular antioxidant status orchestrated by NRFARE pathway that needs further scrutiny. Reports of an improved homing of stem cells following melatonin priming have been reported in experimentally induced liver toxicity in rats [19] and the same can also be assumed to be responsible for an improvement in the therapeutic response and status of HFFD-fed NAFLD mice following Mel.MSC treatment.

\section{Conclusions}

Therapeutic response of ADMSCs shows an improvement in HFFD-mediated NAFLD in C57BL/6J mice by priming the cells with melatonin. Overall, melatonin priming of MSCs is an effective therapeutic strategy that can be scaled-up for bench-to-bedside studies involving lifestyle disorders.

\begin{abstract}
Abbreviations
ALT: Alanine aminotransferase; AST: Aspartate aminotransferase; CMH2-DCFDA: 2,7-dichlorodihydrofluoroscein diacetate; CTCF: Corrected total cell fluorescence; DMEM: Dulbecco's; : modified Eagle's medium; DMSO: Dimethyl sulphoxide; FBS: Fetal bovine serum; HDL-C: High-density lipoprotein cholesterol; HFD: High-fat diet; HFFD: High-fat high-fructose diet; HXE: Hematoxylin and eosin; JC-1: 5, ', ',6,6'-tetrachloro-1,1',3,3'-tetraethylbenzim idazolcarbocyanine iodide; LPS: Lipopolysaccharide; Mel.MSC: Melatoninprimed MSCs; Mel: Melatonin; MSCs: Mesenchymal stem cells; MTT: 3-(4, 5-dimethylthiazol-2-yl)-2, 5-diphenyl tetrazolium bromide; NAFLD: Nonalcoholic fatty liver disease; NASH: Non-alcoholic steatohepatitis; NO: Nitric oxide; PrPC: Cellular prion protein; RT-PCR: Reverse transcriptase polymerase chain reaction; TC: Total cholesterol; TG: Triglycerides; TL: Total lipids; TPVG: Trypsin phosphate versene glucose; UCP2: Uncoupling protein 2; VLDL: Very low-density lipoprotein.
\end{abstract}

\section{Supplementary Information}

The online version contains supplementary material available at https://doi. org/10.1186/s43066-021-00157-w.

Additional file 1: Figure S1 Flow cytometry analysis of AD-MSCs for MSC markers CD44 and CD105 and hematopoietic stem cell marker CD34 and CD45. Figure S2 (a) Food intake and water intake (b) Body weight gain, liver weight and liver: body weight ratio of Control, HFFD, HFFD+MSC and HFFD+Mel.MSC.

\section{Acknowledgements}

Authors acknowledge Prof. Rajesh Singh, Department of Biochemistry, MSU Baroda for use of thermal cycler and Dr. Kishore Rajput, Department of Botany, MSU Baroda for microscopy. Valuable inputs by Ms. Kavita Shirsath are also duly acknowledged.

\section{Authors' contributions}

Study was conceptualized and executed by AHV and RVD. ASJ performed the animal experimentation and biochemical studies. HSV and JT performed stem cell isolation and in vitro experimentation. AHV and KKU performed the microscopy studies. Manuscript was written by AHV and RVD. All authors have read and approved the final manuscript.

\section{Funding}

Major research project sanctioned to RVD as Principal investigator by Gujarat State Biotechnology Mission (GSBTM/MD/PROJECT/SSA/5067/2016-17). The funders had no role in the study design, data collection and analysis, decision to publish, or preparation of the manuscript.

\section{Availability of data and materials}

Data generated or analyzed during this study are included herein.

\section{Declarations}

\section{Ethics approval and consent to participate}

All animal experiments were in compliance with the ethical standards of the Committee for the Purpose of Control and Supervision of Experiments on Animals (CPCSEA), India, with prior approved by Institutional Animal Ethical Committee (IAEC), Department of Zoology, The Maharaja Sayajirao University of Baroda (MSU/Z/IAEC/05-2017). 


\section{Consent for publication \\ Not applicable.}

\section{Competing interests}

The authors declare that they have no competing interests.

\section{Author details}

'Division of Metabolic Physiology and Endocrinology, Department of Zoology, Faculty of Science, The Maharaja Sayajirao University of Baroda, Vadodara, Gujarat 390002, India. 'Department of Internal Medicine, Division of Gastroenterology \& Hepatology, University of Michigan Medical School, Ann Arbor, Michigan, USA. ${ }^{3}$ Total Potential Cells (P) Ltd., 1st floor Parimal Majumdar Wada, Pratap road, Raopura, Vadodara, Gujarat 390001, India.

\section{Received: 17 March 2021 Accepted: 7 November 2021}

Published online: 21 December 2021

\section{References}

1. Rakha M, Saleh O, Abdelgawad MS, El Baiomy A (2021) Helicobacter pylori infection in patients with metabolic syndrome, with or without nonalcoholic fatty liver disease. Egypt Liver J 11:1-9

2. Awaad AK, Kamel MA, Mohamed MM, Helmy MH, Youssef MI, Zaki El, Essawy MM, Hegazy MGA (2020) The role of hepatic transcription factor CAMP response element-binding protein (CREB) during the development of experimental nonalcoholic fatty liver: a biochemical and histomorphometric study. Egypt Liver J 10:1-13

3. Oni ET, Agatston AS, Blaha MJ, Fialkow J, Cury R, Sposito A, Erbel R, Blankstein R, Feldman T, Al-Mallah MH (2013) A systematic review: burden and severity of subclinical cardiovascular disease among those with nonalcoholic fatty liver; should we care? Atherosclerosis 230:258-267

4. Jadeja R, Devkar RV, Nammi S (2014) Herbal medicines for the treatment of nonalcoholic steatohepatitis: current scenario and future prospects. Evid-Based Complement Altern Med 2014:1-19

5. Bulut O, Gürsel i (2020) Mesenchymal stem cell derived extracellular vesicles: promising immunomodulators against autoimmune, autoinflammatory disorders and SARS-CoV-2 infection. Turk J Biol 44:273-282

6. Bolamperti S, Guidobono F, Rubinacci A, Villa I (2019) The role of growth hormone in mesenchymal stem cell commitment. Int J Mol Sci 20:5264

7. Ortiz LA, Gambelli F, McBride C, Gaupp D, Baddoo M, Kaminski N, Phinney DG (2003) Mesenchymal stem cell engraftment in lung is enhanced in response to bleomycin exposure and ameliorates its fibrotic effects. Proc Natl Acad Sci 100:8407-8411

8. Sakaida I, Terai S, Yamamoto N, Aoyama K, Ishikawa T, Nishina H, Okita K (2004) Transplantation of bone marrow cells reduces CCl4-induced liver fibrosis in mice. Hepatology 40:1304-1311

9. Wang $\mathrm{H}$, Zhang $\mathrm{H}$, Huang $\mathrm{B}$, Miao G, Yan X, Gao G, Luo Y, Chen H, Chen W, Yang $L$ (2018) Mesenchymal stem cells reverse high-fat diet-induced nonalcoholic fatty liver disease through suppression of CD4+ T lymphocytes in mice. Mol Med Rep 17:3769-3774

10. Domingues CC, Kundu N, Kropotova Y, Ahmadi N, Sen S (2019) Antioxidant-upregulated mesenchymal stem cells reduce inflammation and improve fatty liver disease in diet-induced obesity. Stem Cell Res Ther 10:1-10

11. Ju S, Teng G-J, Lu H, Jin J, Zhang Y, Zhang A, Ni Y (2010) In vivo differentiation of magnetically labeled mesenchymal stem cells into hepatocytes for cell therapy to repair damaged liver. Investig Radiol 45:625-633

12. Tsuchiya A, Kojima Y, Ikarashi S, Seino S, Watanabe Y, Kawata Y, Terai S (2017) Clinical trials using mesenchymal stem cells in liver diseases and inflammatory bowel diseases. Inflamm Regen 37:1-15

13. Togel F, Hu Z, Weiss K, Isaac J, Lange C, Westenfelder C (2005) Administered mesenchymal stem cells protect against ischemic acute renal failure through differentiation-independent mechanisms. Am J Physiol Physiol 289:F31-F42

14. Wang X-J, Li Q-P (2007) The roles of mesenchymal stem cells (MSCs) therapy in ischemic heart diseases. Biochem Biophys Res Commun 359:189-193
15. Harting MT, Jimenez F, Xue H, Fischer UM, Baumgartner J, Dash PK, Cox CS (2009) Intravenous mesenchymal stem cell therapy for traumatic brain injury. J Neurosurg 110:1189-1197

16. Liu Y, Mu R, Wang S, Long L, Liu X, Li R, Sun J, Guo J, Zhang X, Guo J (2010) Therapeutic potential of human umbilical cord mesenchymal stem cells in the treatment of rheumatoid arthritis. Arthritis Res Ther 12:1-13

17. Nisa GÜL, Gökmen K, Yandim MK, Aysun A, Baran Y (2018) A minimally invasive transfer method of mesenchymal stem cells to the intact periodontal ligament of rat teeth: a preliminary study. Turk J Biol 42:382-391

18. Westminster CO, Westminister CO, Vail CO, Busse D (2008) Increased knee cartilage volume in degenerative joint disease using percutaneously implanted, autologous mesenchymal stem cells. Pain Physician 11:343-353

19. Mortezaee K, Pasbakhsh P, Kashani IR, Sabbaghziarani F, Omidi A, Zendedel A, Ghasemi S, Dehpour AR (2016) Melatonin pretreatment enhances the homing of bone marrow-derived mesenchymal stem cells following transplantation in a rat model of liver fibrosis. Iran Biomed J 20:207

20. Lynch HJ, Ozaki Y, Shakal D, Wurtman RJ (1975) Melatonin excretion of man and rats: effect of time of day, sleep, pinealectomy and food consumption. Int J Biometeorol 19:267-279

21. Rodriguez C, Mayo JC, Sainz RM, Antolín I, Herrera F, Martín V, Reiter RJ (2004) Regulation of antioxidant enzymes: a significant role for melatonin. J Pineal Res 36:1-9

22. Alghamdi BS (2018) The neuroprotective role of melatonin in neurological disorders. J Neurosci Res 96:1136-1149

23. Sainz RM, Mayo JC, Reiter RJ, Antolín I, Esteban MM, Rodríguez C (1999) Melatonin regulates glucocorticoid receptor: an answer to its antiapoptotic action in thymus. FASEB J 13:1547-1556

24. Sun H, Wang X, Chen J, Song K, Gusdon AM, Li L, Bu L, Qu S (2016) Melatonin improves non-alcoholic fatty liver disease via MAPK-JNK/P38 signaling in high-fat-diet-induced obese mice. Lipids Health Dis 15:1-8

25. Li H, Zhang Y, Liu S, Li F, Wang B, Wang J, Cao L, Xia T, Yao Q, Chen H (2019) Melatonin enhances proliferation and modulates differentiation of neural stem cells via autophagy in hyperglycemia. Stem Cells 37:504-515

26. Heo JS, Pyo S, Lim J, Yoon DW, Kim BY, Kim J, Kim GJ, Lee SG, Kim J (2019) Biological effects of melatonin on human adipose-derived mesenchymal stem cells. Int J Mol Med 44:2234-2244

27. Shah SA, Khan M, Jo M, Jo MG, Amin FU, Kim MO (2017) Melatonin stimulates the SIRT 1/Nrf2 signaling pathway counteracting lipopolysaccharide (LPS)-induced oxidative stress to rescue postnatal rat brain. CNS Neurosci Ther 23:33-44

28. Rodríguez-Lozano FJ, García-Bernal D, de los Ángeles Ros-Roca M, del Carmen Algueró M, Onate-Sánchez RE, Camacho-Alonso F, Moraleda JM (2015) Cytoprotective effects of melatonin on zoledronic acid-treated human mesenchymal stem cells in vitro. J Cranio-Maxillofacial Surg 43:855-862

29. Solís-Muñoz P, Solís-Herruzo JA, Fernández-Moreira D, Gómez-Izquierdo E, García-Consuegra I, Muñoz-Yagüe T, García Ruiz I (2011) Melatonin improves mitochondrial respiratory chain activity and liver morphology in ob/ob mice. J Pineal Res 51:113-123

30. Stacchiotti A, Grossi I, García-Gómez R, Patel GA, Salvi A, Lavazza A, De Petro G, Monsalve M, Rezzani R (2019) Melatonin effects on non-alcoholic fatty liver disease are related to microRNA-34a-5p/Sirt1 axis and autophagy. Cells 8:1053

31. Wang H, Wang D, Yang L, Wang Y, Jia J, Na D, Chen H, Luo Y, Liu C (2017) Compact bone-derived mesenchymal stem cells attenuate nonalcoholic steatohepatitis in a mouse model by modulation of CD4 cells differentiation. Int Immunopharmacol 42:67-73

32. Mishra A, Paul S, Swarnakar S (2011) Downregulation of matrix metalloproteinase- 9 by melatonin during prevention of alcohol-induced liver injury in mice. Biochimie 93:854-866

33. Yu G, Wu X, Kilroy G, Halvorsen Y-DC, Gimble JM, Floyd ZE (2011) Isolation of murine adipose-derived stem cells. In: Adipose-Derived Stem Cells. Springer, pp 29-36

34. Ara C, Kirimlioglu H, Karabulut AB, Coban S, Hascalik S, Celik O, Yilmaz S, Kirimlioglu V (2005) Protective effect of melatonin against oxidative stress on adhesion formation in the rat cecum and uterine horn model. Life Sci 77:1341-1350

35. Uz T, Giusti P, Franceschini D, Kharlamov A, Manev H (1996) Protective effect of melatonin against hippocampal DNA damage induced by intraperitoneal administration of kainate to rats. Neuroscience 73:631-636 
36. Thounaojam MC, Jadeja RN, Valodkar M, Nagar PS, Devkar RV, Thakore S (2011) Oxidative stress induced apoptosis of human lung carcinoma (A549) cells by a novel copper nanorod formulation. Food Chem Toxicol 49:2990-2996

37. Upadhyay KK, Jadeja RN, Thadani JM, Joshi A, Vohra A, Mevada V, Patel R, Khurana S, Devkar RV (2018) Carbon monoxide releasing molecule A-1 attenuates acetaminophen-mediated hepatotoxicity and improves survival of mice by induction of Nrf2 and related genes. Toxicol Appl Pharmacol 360:99-108

38. Cai B, Li X, Wang Y, Liu Y, Yang F, Chen H, Yin K, Tan X, Zhu J, Pan Z (2013) Apoptosis of bone marrow mesenchymal stem cells caused by homocysteine via activating JNK signal. PLoS One 8:e63561

39. Huang D, Yin L, Liu X, Lv B, Xie Z, Wang X, Yu B, Zhang Y (2018) Geraniin protects bone marrow-derived mesenchymal stem cells against hydrogen peroxide-induced cellular oxidative stress in vitro. Int J Mol Med 41:739-748

40. Upadhyay KK, Jadeja RN, Vyas HS, Pandya B, Joshi A, Vohra A, Thounaojam MC, Martin PM, Bartoli M, Devkar RV (2020) Carbon monoxide releasing molecule-A1 improves nonalcoholic steatohepatitis via Nrf2 activation mediated improvement in oxidative stress and mitochondrial function. Redox Biol 28:101314

41. Janssen BJA, De Celle T, Debets JJM, Brouns AE, Callahan MF, Smith TL (2004) Effects of anesthetics on systemic hemodynamics in mice. Am J Physiol Circ Physiol 287:H1618-H1624

42. Dardai E, Heavner JE (1987) Respiratory and cardiovascular effects of halothane, isoflurane and enflurane delivered via a Jackson-Rees breathing system in temperature controlled and uncontrolled rats. Methods Find Exp Clin Pharmacol 9:717-720

43. Njoku D, Laster MJ, Gong DH, Eger El, Reed GF, Martin JL (1997) Biotransformation of halothane, enflurane, isoflurane, and desflurane to trifluoroacetylated liver proteins: association between protein acylation and hepatic injury. Anesth Analg 84:173-178

44. He S, Atkinson C, Qiao F, Chen X, Tomlinson S (2010) Ketamine-xylazine-acepromazine compared with isoflurane for anesthesia during liver transplantation in rodents. J Am Assoc Lab Anim Sci 49:45-51

45. Andersson U, Bränning C, Ahrné S, Molin G, Alenfall J, Önning G, Nyman M, Holm C (2010) Probiotics lower plasma glucose in the high-fat fed C57BL/6J mouse. Benefic Microbes 1:189-196

46. Shirsath K, Joshi A, Vohra A, Devkar R (2021) Chronic photoperiodic manipulation induced chronodisruption upregulates HSP60 during early pro-atherogenic remodeling in thoracic aorta of $\mathrm{C} 57 \mathrm{BL} / 6 \mathrm{~J}$ mice. J Basic Appl Zool 82:1-10

47. Shirsath K, Joshi A, Vohra A, Devkar R (2021) HSP60 knockdown exerts differential response in endothelial cells and monocyte derived macrophages during atherogenic transformation. Sci Rep 11:1-17

48. Kuo TK, Hung S, Chuang C, Chen C, Shih YV, Fang SY, Yang VW, Lee OK (2008) Stem cell therapy for liver disease: parameters governing the success of using bone marrow mesenchymal stem cells. Gastroenterology 134:2111-2121

49. Menon D, Coll R, Board PG (2014) Glutathione transferase omega 1 is required for the lipopolysaccharide-stimulated induction of NADPH oxidase 1 and the production of reactive oxygen species in macrophages. Free Radic Biol Med 73:318-327

50. Wang J, Li L, Wang Z, Cui Y, Tan X, Yuan T, Liu Q, Liu Z, Liu X (2018) Supplementation of lycopene attenuates lipopolysaccharide-induced amyloidogenesis and cognitive impairments via mediating neuroinflammation and oxidative stress. J Nutr Biochem 56:16-25

51. Emre Y, Hurtaud C, Nübel T, Criscuolo F, Ricquier D, Cassard-Doulcier A-M (2007) Mitochondria contribute to LPS-induced MAPK activation via uncoupling protein UCP2 in macrophages. Biochem J 402:271-278

52. Arioz BI, Tastan B, Tarakcioglu E, Tufekci KU, Olcum M, Ersoy N, Bagriyanik A, Genc K, Genc S (2019) Melatonin attenuates LPS-induced acute depressive-like behaviors and microglial NLRP3 inflammasome activation through the SIRT1/Nrf2 pathway. Front Immunol 10:1511

53. Lee JH, Yoon YM, Han Y, Jung SK, Lee SH (2019) Melatonin protects mesenchymal stem cells from autophagy-mediated death under ischaemic ER-stress conditions by increasing prion protein expression. Cell Prolif 52:e12545

54. Fang J, Yan Y, Teng X, Wen X, Li N, Peng S, Liu W, Donadeu FX, Zhao S, Hua J (2018) Melatonin prevents senescence of canine adipose-derived mesenchymal stem cells through activating NRF2 and inhibiting ER stress. Aging (Albany NY) 10:2954

55. Su GL, Klein RD, Aminlari A, Zhang HY, Steinstraesser L, Alarcon WH, Remick DG, Wang SC (2000) Kupffer cell activation by lipopolysaccharide in rats: role for lipopolysaccharide binding protein and toll-like receptor 4. Hepatology 31:932-936

56. Cassatella MA, Meda L, Bonora S, Ceska M, Constantin G (1993) Interleukin 10 (IL-10) inhibits the release of proinflammatory cytokines from human polymorphonuclear leukocytes. Evidence for an autocrine role of tumor necrosis factor and IL-1 beta in mediating the production of IL-8 triggered by lipopolysaccharide. J Exp Med 178:2207-2211

57. Lee JH, Han Y, Lee SH (2017) Potentiation of biological effects of mesenchymal stem cells in ischemic conditions by melatonin via upregulation of cellular prion protein expression. J Pineal Res 62:e12385

58. Jung Y-A, Choi Y-K, Jung G-S, Seo H-Y, Kim H-S, Jang BK, Kim J-G, Lee I-K, Kim M-K, Park K-G (2014) Sitagliptin attenuates methionine/cholinedeficient diet-induced steatohepatitis. Diabetes Res Clin Pract 105:47-57

59. Wortham M, He L, Gyamfi M, Copple BL, Wan Y-JY (2008) The transition from fatty liver to NASH associates with SAMe depletion in $\mathrm{db} / \mathrm{db}$ mice fed a methionine choline-deficient diet. Dig Dis Sci 53:2761-2774

60. Li B, Cheng Y, Yu S, Zang L, Yin Y, Liu J, Zhang L, Mu Y (2019) Human umbilical cord-derived mesenchymal stem cell therapy ameliorates nonalcoholic fatty liver disease in obese type 2 diabetic mice. Stem Cells Int 2019:1-12

61. Jadeja RN, Thounaojam MC, Dandekar DS, Devkar RV, Ramachandran AV (2010) Clerodendron glandulosum. Coleb extract ameliorates high fat diet/fatty acid induced lipotoxicity in experimental models of non-alcoholic steatohepatitis. Food Chem Toxicol 48:3424-3431

62. Driscoll J, Patel T (2019) The mesenchymal stem cell secretome as an acellular regenerative therapy for liver disease. J Gastroenterol 54:763-773

63. Zhang S, Chen L, Liu T, Zhang B, Xiang D, Wang Z, Wang Y (2012) Human umbilical cord matrix stem cells efficiently rescue acute liver failure through paracrine effects rather than hepatic differentiation. Tissue Eng part A 18:1352-1364

\section{Publisher's Note}

Springer Nature remains neutral with regard to jurisdictional claims in published maps and institutional affiliations.

\section{Submit your manuscript to a SpringerOpen ${ }^{\circ}$ journal and benefit from:}

- Convenient online submission

- Rigorous peer review

- Open access: articles freely available online

- High visibility within the field

- Retaining the copyright to your article

Submit your next manuscript at springeropen.com 